\title{
Assessing Hazards Along Our Nation's Coasts
}

\author{
Understanding and Forecasting Impacts to Coastal Communities
}

Coastal areas are essential to the economic, cultural, and environmental health of the Nation, yet by nature coastal areas are constantly changing due to a variety of events and processes. Extreme storms can cause dramatic changes to our shorelines in a matter of hours, while sea-level rise can profoundly alter coastal environments over decades. These changes can have a devastating impact on coastal communities, such as the loss of homes built on retreating sea cliffs or protective dunes eroded by storm waves. Sometimes, however, the changes can be positive, such as new habitat created by storm deposits. The U.S. Geological Survey (USGS) is meeting the need for scientific understanding of how our coasts respond to different hazards with continued assessments of current and future changes along U.S. coastlines. Through the National Assessment of Coastal Change Hazards (NACCH), the USGS carries out the unique task of quantifying coastal change hazards along open-ocean coasts in the United States and its territories. Residents of coastal communities, emergency managers, and other stakeholders can use science-based data, tools, models, and other products to improve planning and enhance resilience.

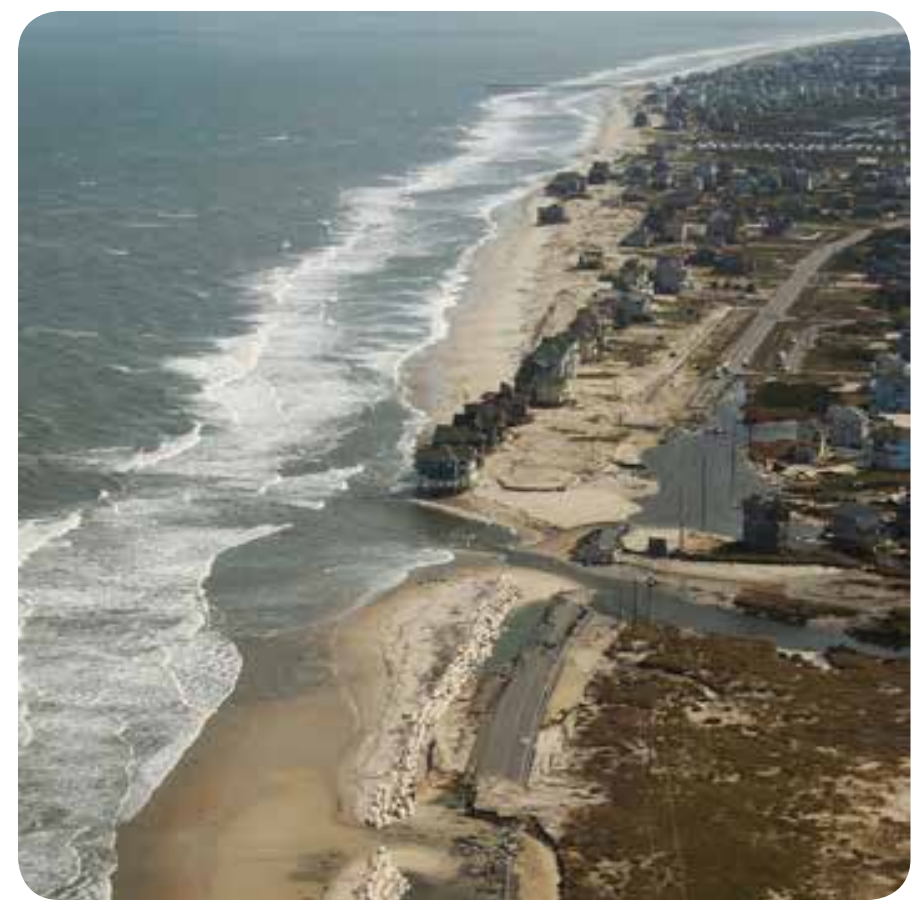

Figure 1. Three days after landfall of Hurricane Irene in 2011, the powerful effects of coastal change can be seen along the coast of Rodanthe, N.C. Waves and storm surge eroded and breached the dunes, transported sand landward, and removed a section of roadway. This area has been repeatedly affected by major storms, leaving the community wrestling with the costs of maintaining infrastructure and community safety.

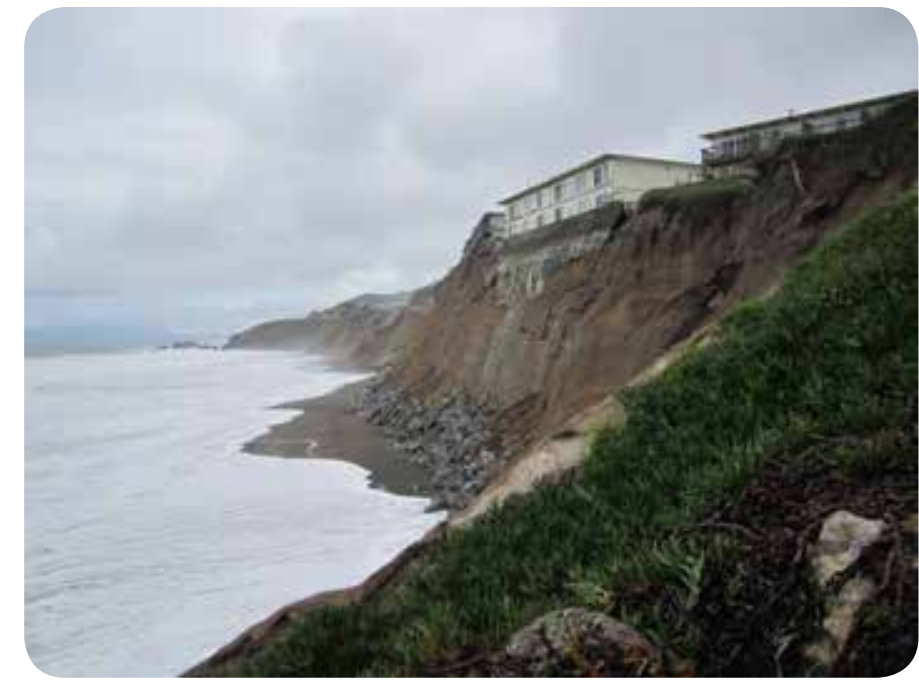

Figure 2. Houses near the edge of a rapidly eroding section of cliff in Pacifica, Calif., illustrate the risk that sea cliff erosion poses to residences and infrastructure in many locations along the U.S. west coast. (Photograph by Gary Griggs, University of California, Santa Cruz)

\section{What is the National Assessment of Coastal Change Hazards?}

USGS scientists are working to uncover the ways in which our coasts have changed — and will continue to change - over time. NACCH uses a multifaceted approach that quantifies key factors shaping our shorelines over multiple timescales-some that occur in minutes, others over a century. Scientists examine coastal processes, including extreme storms, long-term shoreline change, and sea-level rise. Through extensive observation, modeling, and prediction of these processes, scientists document how U.S. shores have historically shifted and how past changes affect vulnerability to future hazards.

\section{Understanding and Forecasting Storm Impacts}

Hurricanes, nor'easters, and Pacific winter storms are powerful events that generate dangerous waves and storm surge capable of moving large amounts of sand, destroying buildings and infrastructure, and even taking lives. Storm processes like beach and dune erosion, overwash, cliff failure, and coastal inundation continually reshape our Nation's coastline. One component of $\mathrm{NACCH}$ focuses on understanding the magnitude and variability of the impact of sandy beaches. The objective is to improve real-time and scenario-based forecasts of coastal change to support planning and management decisions. 


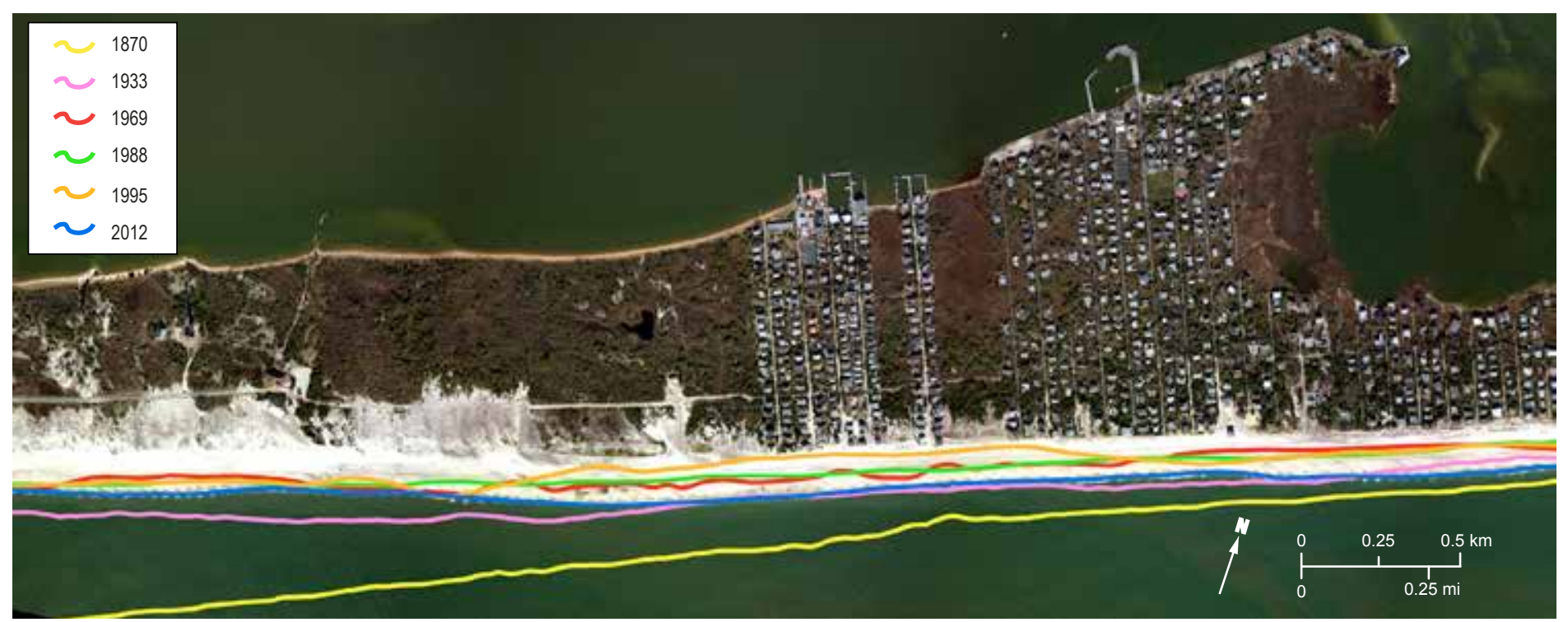

Figure 3. An aerial photograph of Fire Island, N.Y., taken less than a week after Hurricane Sandy in 2012, is overlain by historical and recent shoreline positions. These shorelines illustrate more than 140 years of coastal change. Over 250 meters (820 feet) of shoreline retreat has taken place on the western part of the island. Rates of shoreline change can be calculated and analyzed using the publicly available USGS Digital Shoreline Analysis System.

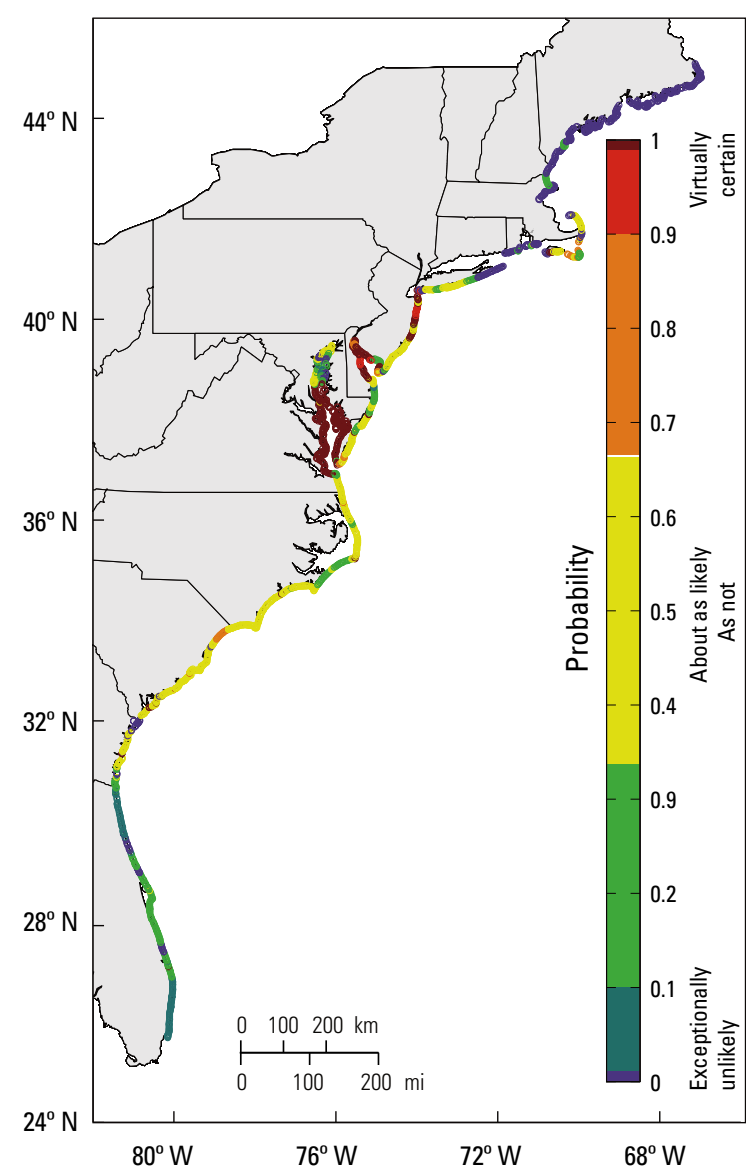

Figure 4. Areas along the Atlantic coast that are most likely to erode due to future sea-level rise are determined using a model that includes rate of long-term shoreline change, rate of long-term sea-level rise, coastal slope, geomorphic setting, tidal range, and wave height. Likelihoods of shoreline change can be used by planners and land managers to inform communities about longterm hazards.

\section{Measuring Long-Term Change}

Erosion is a chronic problem along most open-ocean shores of the United States and is an increasing threat to growing coastal populations. As beaches erode - at increasing rates in some areas - there is a demand for accurate information regarding changes in shoreline position. Knowing how the coast has changed in the past, and what factors influenced those changes, guides our understanding of what may happen in the future. To meet the needs of coastal managers and policy makers, the USGS has produced a nationally consistent analysis of shoreline positions and maps of changes along open-ocean coasts of the conterminous United States and parts of Alaska and Hawaii.

\section{Understanding Vulnerability to Sea-Level Rise}

As our oceans rise, today's coastal floods will become tomorrow's high tides. USGS research is assessing the potential impacts of sea-level rise and providing tools for coastal management decision making. USGS scientists use historical and recent observations of coastal change combined with model simulations of beaches, barrier islands, wetlands, and coastal aquifers to determine the probability of coastal change and other impacts associated with sea-level rise. This information is shared with managers who face decisions about how to avoid, mitigate, or adapt to future hazards.

\section{Sharing Science-Based Assessments}

As storms continue to impact our coasts and sea levels continue to rise, coastal communities will be faced with difficult decisions regarding development and management practices. The NACCH provides science-based vulnerability assessments to partner agencies, policy makers, and residents to inform strategies for preparing for, mitigating, and responding to our constantly changing coastlines.

\section{For additional information:}

http://marine.usgs.gov/coastalchangehazards/

http://marine.usgs.gov/coastalchangehazardsportal/

USGS, St. Petersburg Coastal and Marine Science Center, Florida (727) 803-8747 USGS, Woods Hole Coastal and Marine Science Center, Massachusetts (508) 548-8700 USGS, Pacific Coastal and Marine Science Center, Santa Cruz, California (831) 427-4450 